\title{
Pre-emptive analgesia using intravenous fentanyl plus low-dose ketamine for radical prostatectomy under general anesthesia does not produce short-term or long-term reductions in pain or analgesic use
}

\author{
Joel Katz ${ }^{\mathrm{a}, \mathrm{b}, \mathrm{c}, *}$, Roger Schmid ${ }^{\mathrm{b}, 1}$, Dirk G. Snijdelaar ${ }^{\mathrm{d}}$, Terence J. Coderre ${ }^{\mathrm{e}}$, \\ Colin J.L. McCartney ${ }^{\mathrm{b}, \mathrm{c}}$, Adarose Wowk ${ }^{\mathrm{b}, 2}$ \\ ${ }^{\mathrm{a}}$ Department of Psychology and School of Kinesiology and Health Science, York University, Toronto, Ont., Canada \\ ${ }^{\mathrm{b}}$ Department of Anesthesia and Pain Management, University Health Network and Mount Sinai Hospital, Toronto, Ont., Canada \\ ${ }^{\mathrm{C}}$ Department of Anesthesia, University of Toronto, Toronto, Ont., Canada \\ ${ }^{\mathrm{d}}$ Department of Anesthesiology/Pain Centre, University Medical Centre Nijmegen, Nijmegen, The Netherlands \\ ${ }^{e}$ Departments of Anesthesia, Neurology and Neurosurgery and Psychology, McGill University; McGill University Health Centre Research Institute and McGill \\ Centre for Research on Pain, Montreal, Que., Canada
}

\begin{abstract}
The aim of the study was to evaluate post-operative pain and analgesic use after pre-operative or post-incisional i.v. fentanyl plus low dose i.v. ketamine vs. a standard treatment receiving i.v. fentanyl but not ketamine. Men undergoing radical prostatectomy under general anesthesia were randomly assigned in a double-blinded manner to one of three groups. Patients received i.v. fentanyl before incision followed by an i.v. bolus dose $\left(0.2 \mathrm{ml} \mathrm{kg}^{-1}\right)$ and an i.v. infusion $\left(0.0025 \mathrm{ml} \mathrm{kg}^{-1} \mathrm{~min}^{-1}\right)$ of $1 \mathrm{mg} \mathrm{ml}^{-1}$ ketamine (group 1) or normal saline (groups 2 and 3 ). Seventy minutes after incision, patients received i.v. fentanyl followed by an i.v. bolus dose $\left(0.2 \mathrm{ml} \mathrm{kg}{ }^{-1}\right)$ and an i.v. infusion $\left(0.0025 \mathrm{ml} \mathrm{kg}^{-1} \mathrm{~min}^{-1}\right)$ of saline (groups 1 and 3) or ketamine (group 2). Pain, von Frey pain thresholds, and cumulative morphine consumption using patient-controlled analgesia (PCA) were assessed up to $72 \mathrm{~h}$ after surgery. 143 patients completed the study (group $1, n=47$; group $2, n=50$; group $3, n=46$ ). Cumulative PCA morphine (mean $\pm \mathrm{SD}$ ) did not differ significantly among groups (group 1, $92.3 \pm 45.9 \mathrm{mg}$; group 2, $107.2 \pm 58.4 \mathrm{mg}$; group $3,103.6 \pm 50.4 \mathrm{mg} ; P=0.08$ for groups 1 vs. 2 , and groups 1 vs. 3 ). On day 3 , the hourly rate (mean \pm SEM) of morphine consumption was significantly lower $(P<0.0009)$ in group $1\left(0.61 \pm 0.013 \mathrm{mg} \mathrm{h}^{-1}\right)$ than group $2\left(0.86 \pm 0.011 \mathrm{mg} \mathrm{h}^{-1}\right)$ and group $3\left(0.89 \pm 0.008 \mathrm{mg} \mathrm{h}^{-1}\right)$. Pain scores and von Frey pain thresholds did not differ significantly among groups. Two-week and 6-month follow-ups did not reveal significant group differences in pain incidence, intensity, disability or mental health. Pre-operative, low-dose administration of i.v. ketamine did not result in a clinically meaningful reduction in pain or morphine consumption when compared with post-incisional administration of ketamine or a saline control condition.
\end{abstract}

Keywords: Analgesia; Fentanyl; Ketamine

\section{Introduction}

Ketamine hydrochloride operates on multiple receptor systems (Schmid et al., 1999). However, its property as a non-competitive NMDA receptor antagonist generated

\footnotetext{
* Corresponding author. Address: Department of Anesthesia and Pain Management, Toronto General Hospital, EN 3-440, 200 Elizabeth Street, Toronto, Ont., Canada M5G 2C4. Tel.: +1-416-340-3777; fax: +1-416340-3698.

E-mail address: jkatz@uhnres.utoronto.ca (J. Katz).

${ }^{1}$ Present address: Klinik Links vom Rhein, Cologne, Germany.

${ }^{2}$ Present address: Clinical Trials Monitor, Aventis Pharma, Toronto, Ont., Canada.
}

a new focus of research activity once this receptor-ion channel complex was found to play a critical role in the induction and maintenance of central sensitization and pathological pain (Wilcox, 1991; Woolf and Thompson, 1991). The mechanism by which pain and analgesic consumption are reduced after pre-emptive administration of local anesthetics and opioids is believed to involve the prevention of NMDA-mediated sensitization of spinal cord dorsal horn neurons (Kissin, 2000; Woolf and Chong, 1993). Thus, the NMDA channel blocker ketamine has been of particular interest in evaluating the hypothesis that ketamine administration before surgery would reduce pain 
and analgesic consumption relative to saline administration or to ketamine administration after incision.

Studies of pre-emptive analgesia using intravenous lowdose ketamine have yielded mixed results (Katz, 2003; McCartney et al., 2004; Schmid et al., 1999) This is in part due to the large inter-study variability in surgical procedure, patient population, dose of ketamine, use of additional analgesic agents intraoperatively and study design. One of the aims of the present study was to evaluate the effects on post-operative pain and morphine consumption of preincisional vs. post-incisional i.v. administration of the mu opioid agonist fentanyl plus low-dose ketamine. Use of these two agents together would be expected to capitalize on their combined actions in reducing nociceptive input and central sensitization (Chapman and Dickenson, 1992; Dickenson, 1997). We hypothesized that morphine consumption would be lower in the pre-incisional group compared with the post-incisional group.

Debate about the efficacy of pre-emptive analgesia stems in part from a fundamental misconception about its definition (Katz, 2003; Kissin, 2000). The typical twogroup design that compares administration of an agent before vs. after incision or surgery fails to control for the possibility that early and late noxious intraoperative stimuli contribute equally to post-operative central sensitization. Two group studies that do not show a significant difference in outcome leave open the question of whether the absence of an effect reflects the relative efficacy of post-operative blockade or the inefficacy of pre-operative blockade in reducing central sensitization (Katz, 2003; Katz et al., 2003).

Therefore, the second aim of the present study was to evaluate post-operative pain and analgesic use after preoperative or post-incisional i.v. fentanyl plus low dose i.v. ketamine vs. a standard treatment control condition consisting of i.v. fentanyl but not ketamine. Men undergoing radical prostatectomy under general anesthesia were randomly assigned in a double-blinded manner to one of three groups: (1) i.v. fentanyl plus low dose i.v. ketamine (bolus plus infusion) before incision and i.v. fentanyl plus saline (bolus plus infusion) after incision; (2) i.v. fentanyl plus i.v. saline (bolus plus infusion) before incision and i.v. fentanyl plus low dose i.v. ketamine (bolus plus infusion) after incision; or (3) i.v. fentanyl plus i.v. saline (bolus plus infusion) before and after incision. We hypothesized that post-operative pain and morphine consumption would be lowest in the pre-incision group and highest in the control group.

\section{Materials and methods}

Approval to carry out the study was obtained from The Toronto Hospital Research Ethics Board. All patients gave their written informed consent to participate before entering the study.
Patients scheduled for radical prostatectomy for prostate cancer were eligible for recruitment into the study. Inclusion criteria were American Society of Anesthesiologists physical status I-II, age between 19 and 75 years and able to speak and read English. Exclusion criteria were contraindications to (iv) patient-controlled analgesia (PCA) with morphine, American Society of Anesthesiologists physical status > II, history of major psychiatric disorder, and chronic opioid use.

\subsection{Randomization and blinding procedures}

A randomization schedule was computer-generated (Dallal, 1988) and provided to the hospital pharmacist who prepared and dispensed the study drug. The randomization schedule specified the group $(1,2$, or 3$)$ to which each prospective patient would be allocated upon entry into the trial. An opaque envelope containing the patient number and group assignment was prepared, sealed and numbered for each patient by the hospital pharmacist.

All patients and personnel involved in patient management and data collection were unaware of the group to which the patient had been allocated. The anesthesiologist in charge of the case was also unaware of group allocation.

\subsection{Drug preparation}

A standard volume of ketamine hydrochloride and normal saline was prepared in two separate $60 \mathrm{ml}$ syringes, coded for blinding purposes, and dispensed by the hospital pharmacy on the day of surgery. The syringes were labeled 'pre-incision' and 'post-incision'. For group 1 and 2 patients, one syringe contained $60 \mathrm{ml}$ ketamine hydrochloride $\left(1 \mathrm{mg} \mathrm{ml}^{-1}\right)$; the second contained $60 \mathrm{ml}$ normal saline. For group 3 patients, both syringes contained $60 \mathrm{ml}$ normal saline. The pharmacist who dispensed the study medications was not involved in any other aspect of the study.

\subsection{Pain assessment instruments}

\subsubsection{Visual analogue scale (VAS)}

The VAS provides a simple, efficient, and minimally intrusive measure of pain intensity that has been used widely in research settings where a quick index of pain is required and to which a numerical value can be assigned (Katz and Melzack, 1999). The VAS consists of a $10 \mathrm{~cm}$ horizontal line with the two endpoints labeled 'no pain' and 'worst possible pain', respectively. The patient is required to mark the $10 \mathrm{~cm}$ line at a point that corresponds to the level of pain intensity he presently feels. The distance in centimeters from the low end of the VAS and the patient's mark is used as a numerical index of pain intensity. Pain was assessed with patients at rest (VAS-R) and after standard mobilization (VAS-M) by asking patients to roll from a supine to a side-lying position and perform two maximal inspirations before rating their pain. 


\subsubsection{McGill Pain Questionnaire (MPQ)}

The MPQ was developed by Melzack (1975) to obtain quantitative and qualitative measures of the experience of pain. The MPQ yields two global scores, the pain rating index (PRI) and the present pain intensity (PPI), which have been found to provide valid and reliable measures of pain (Katz and Melzack, 1999; Melzack, 1975). The PRI is the sum of the rank values of the words chosen from 20 sets of qualitative words, each set containing $2-6$ adjectives that describe the sensory, affective and evaluative properties of pain. The lists of pain descriptors are read to the patients who are asked to choose the word in each category that best describes their pain at the moment. The PPI is rated on a scale of $0-5$ as follows: 0 , none; 1 , mild; 2 , discomforting; 3 , distressing; 4 , horrible; and 5 , excruciating.

\subsection{3. von Frey filaments}

Secondary mechanical hyperalgesia to punctate stimulation applied to the skin was assessed using von Frey filaments (Smith and Nephew Rolyan Inc., Menomonee Falls, WI) that consist of a set of 20 individual nylon filaments of equal length $(38 \mathrm{~mm})$ ranging from 0.06 to $1.14 \mathrm{~mm}$ in diameter. Each filament has been assigned a value that represents the logarithm of the force (in $\mathrm{mg}$ ) required to bend it maximally when pressed against the skin. To minimize the assessment burden on the patients, we used every other filament beginning with the smallest $(0.06 \mathrm{~mm})$. On each trial, a filament was applied to the designated point on the skin for approximately $1 \mathrm{~s}$. Trials were separated by an interval ranging from 5 to $15 \mathrm{~s}$ in order to reduce the likelihood of anticipatory responses. Filaments were applied in ascending serial order. Touch threshold (TT) was defined by the value (force in $\log \mathrm{mg}$ ) associated with the filament that patients first reported a sensation of touch. Pain threshold (PT) was defined by the value (force in log $\mathrm{mg}$ ) associated with the filament that patients first reported as being uncomfortable or painful. PTs were obtained from two regions of the body: a control site on the inner forearm and a test site approximately $10 \mathrm{~cm}$ from the wound dressing.

\subsection{Measures of psychosocial functioning}

\subsubsection{Mental Health Inventory (MHI)}

The MHI (Ware et al., 1979) is a self-administered questionnaire that measures symptoms of psychological distress and well-being. The present study used an 18-item version of the MHI that consists of a total score and five subscales: anxiety, depression, loss of behavioral/emotional control, positive affect, and interpersonal ties (Weinstein et al., 1989). Subjects responded to each of the 18 statements on the basis of how often 'in the past month' they have experienced each symptom. Each statement is accompanied by a six choice response set ranging from $1=$ all of the time to $6=$ none of the time. The total score, which we report in the present study, ranges from 0 to 108 with higher scores indicative of better mental health. The MHI was administered prior to surgery. Internal reliability of the MHI subscales by Cronbach's alpha ranged from 0.10 (loss of behavioral/emotional control) to 0.85 (depression).

\subsubsection{Spielberger State-Trait Anxiety Inventory (STAI)}

The STAI (Spielberger et al., 1970) is composed of two forms, each of which measures separate dimensions of anxiety. The STAI-S consists of 20 statements and measures 'state anxiety'. The patients are required to respond on the basis of how they are feeling 'right now' (i.e. at the moment when completing the form). The STAI-T measures anxiety as an enduring personality trait and consists of another 20 statements that pertain to how the patients 'generally feel'. The STAI-S has been shown to be sensitive to psychological manipulations that alter anxiety level. Test-retest reliability coefficients of the STAI-T have been reported to be relatively high, reaching approximately 0.70 after a 3-month interval, and increasing with decreasing time between testings. The STAI has also shown relatively high correlations with other well known measures of anxiety. Only the STAI-S was used in the present study. Internal reliability of the STAI-S by Cronbach's alpha was 0.90 .

\subsubsection{Follow-up Pain Questionnaire (FUPQ)}

The FUPQ is a brief inventory designed to assess the presence, intensity, location, frequency, and quality of longterm post-surgical pain. Items also assess pain interference in daily life, methods of pain relief sought, medication use and aggravating and relieving factors. The FUPQ was modeled after similar pain assessment measures including the MPQ (Melzack, 1975) and a follow-up interview form used to assess long-term pain after surgery (Dajczman et al., 1991). The FUPQ was administered at the 6-month postsurgical interview.

\subsection{Procedures}

\subsubsection{Preoperative assessment}

A member of the research team approached prospective patients who were informed of the nature of the study, screened for eligibility and recruited if interested. Following informed written consent, patients completed the MHI and STAI-S. Patients were familiarized with the VAS rating scales and were shown a PCA pump and instructed in its use.

\subsubsection{Pre-incisional and post-incisional administration of ketamine and saline}

On the morning of surgery a research nurse drew up the appropriate volumes (based on the patient's weight) from the two $60 \mathrm{ml}$ coded syringes that had been prepared and dispensed by the pharmacy. The first and second syringes, labeled 'pre-incision' and 'post-incision', respectively, contained ketamine $\left(1 \mathrm{mg} \mathrm{ml}^{-1}\right)$ and saline for group 1 , 


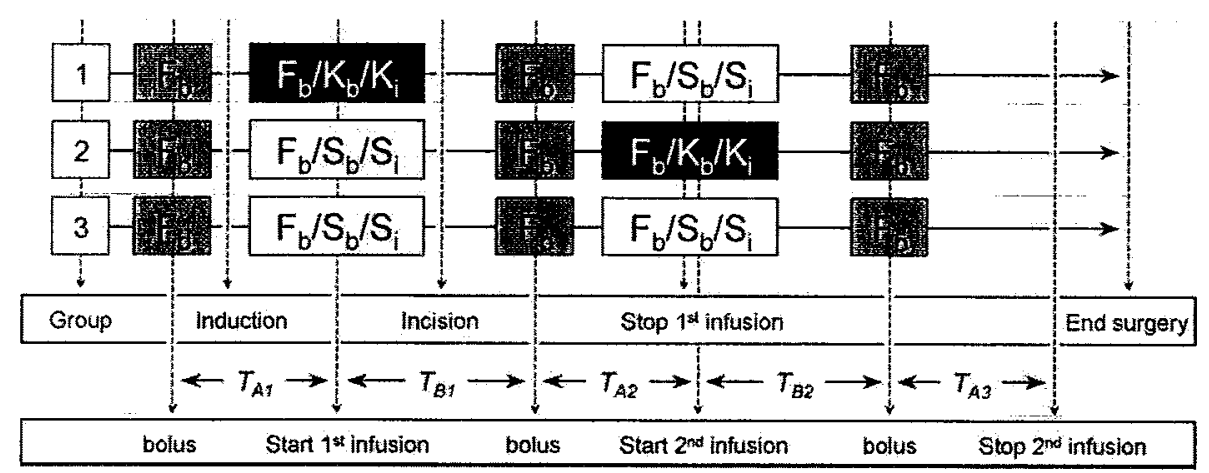

Fig. 1. Flow chart showing timing of drug administration relative to specific pre-operative and intraoperative events. To ensure comparability among groups, time intervals $T_{\mathrm{A} 1}, T_{\mathrm{A} 2}, T_{\mathrm{A} 3}$ and $T_{\mathrm{B} 1}, T_{\mathrm{B} 2}$ were designed to be of equal duration, respectively. See Table 1 for actual duration of each interval. Abbreviations: $\mathrm{F}$, fentanyl; $K$, ketamine; $S$, saline; subscript b, bolus; subscript $i$, infusion.

saline and ketamine $\left(1 \mathrm{mg} \mathrm{ml}^{-1}\right)$ for group 2 , and saline and saline for group 3.

All patients received i.v. fentanyl $\left(1 \mu \mathrm{g} \mathrm{kg}^{-1}\right.$, $25 \mu \mathrm{g} \mathrm{ml}^{-1}$ ) every $80 \mathrm{~min}$ starting approximately $5 \mathrm{~min}$ before induction of general anesthesia (Fig. 1 and Table 1). Approximately $10 \mathrm{~min}$ before skin incision, and after induction of general anesthesia, all patients received a bolus dose of i.v. fentanyl $\left(0.5 \mu \mathrm{g} \mathrm{kg}^{-1}\right)$. This was followed immediately by an i.v. bolus dose $\left(0.2 \mathrm{ml} \mathrm{kg}^{-1}\right)$ and an i.v. infusion $\left(0.0025 \mathrm{ml} \mathrm{kg}^{-1} \mathrm{~min}^{-1}\right)$ from the first syringe labeled 'pre-incision'. Seventy minutes after incision, the first infusion was stopped and all patients received a bolus dose of i.v. fentanyl $\left(0.5 \mu \mathrm{g} \mathrm{kg}^{-1}\right)$. This was followed immediately by an i.v. bolus dose $\left(0.2 \mathrm{ml} \mathrm{kg}^{-1}\right)$ and an i.v. infusion $\left(0.0025 \mathrm{ml} \mathrm{kg}^{-1} \mathrm{~min}^{-1}\right)$ from the second syringe labeled 'post-incision'. The second infusion was stopped after $80 \mathrm{~min}$, approximately $150 \mathrm{~min}$ after incision.

\subsubsection{General anesthesia}

Patients received midazolam $1-2 \mathrm{mg}$ i.v. as premedication approximately $1 \mathrm{~h}$ before surgery. General anesthesia was induced with thiopental $4-6 \mathrm{mg} \mathrm{kg}^{-1}$. Intubation followed the administration of d-tubo curarine (3.0-4.5 mg) and succinylcholine $1.0-1.5 \mathrm{mg} \mathrm{kg}^{-1}$. General anesthesia was maintained with $60 \% \mathrm{~N}_{2} \mathrm{O}$ in $\mathrm{O}_{2}$ and isoflurane. Pancuronium was used for neuromuscular blockade. Vasoactive agents (beta-blockers, vasodilators and vasopressors) were used as required to maintain hemodynamic parameters within $\pm 20 \%$ of mean preoperative baseline values. At the conclusion of the surgery, neuromuscular blockade was reversed with neostigmine $0.05 \mathrm{mg} \mathrm{kg}^{-1}$ and glycopyrrolate $0.02 \mathrm{mg} \mathrm{kg}^{-1}$. The trachea was extubated after emergence and upon resumption of spontaneous breathing. Patients received supplemental $\mathrm{O}_{2}$ by mask and were transported to the post-anesthetic care unit (PACU).

\subsubsection{Intraoperative monitoring}

All patients were continuously monitored with an arterial line (systolic, mean, diastolic blood pressure), electrocardiogram (heart rate and rhythm), pulse oximeter, nasal temperature probe, and end-tidal monitor (anaesthetic gas and carbon dioxide levels). Intra-operative hemodynamics and end-tidal isoflurane were recorded every minute for the first $5 \mathrm{~min}$ after skin incision and every $15 \mathrm{~min}$ thereafter until the end of surgery.

\subsubsection{Postoperative analgesia}

Patients were assessed immediately upon arrival in the PACU and were connected to a PCA pump system (Abbott Life Care Infuser, Abbott Laboratories, Chicago, IL, USA). If patients complained of pain, a research nurse blind to group allocation administered a loading dose of $2-4 \mathrm{mg}$ morphine. Every $5 \mathrm{~min}$, patients were asked whether they were in need of pain relief. An affirmative response was followed by a $1.0-1.5 \mathrm{mg}$ i.v. bolus of morphine.

Table 1

Timing of drug administration relative to intraoperative events (mean \pm SD)

\begin{tabular}{|c|c|c|c|c|}
\hline Time interval (see Fig. 1) & Interval between intraoperative events & Group 1 & Group 2 & Group 3 \\
\hline- & Min between pre-induction dose of fentanyl and induction of GA & $4.6 \pm 3.7$ & $4.8 \pm 3.9$ & $4.8 \pm 3.5$ \\
\hline$T_{\mathrm{A} 1}$ & Min between pre-induction dose of fentanyl and start of infusion 1 & $22.6 \pm 6.1$ & $25.1 \pm 7.0$ & $23.2 \pm 8.2$ \\
\hline- & Min between start of infusion 1 and incision & $9.9 \pm 6.4$ & $9.2 \pm 2.6$ & $9.7 \pm 3.3$ \\
\hline$T_{\mathrm{B} 1}$ & Min between start of infusion 1 and 1 st post-incisional dose of fentanyl & $58.6 \pm 3.8$ & $58.9 \pm 3.4$ & $59.4 \pm 3.3$ \\
\hline$T_{\mathrm{A} 2}$ & Min between 2 nd post-incisional dose of fentanyl and start of infusion 2 & $22.6 \pm 6.7$ & $25.4 \pm 7.3$ & $23.2 \pm 8.2$ \\
\hline$T_{\mathrm{B} 2}$ & Min between start of infusion 2 and 3rd post-incisional dose of fentanyl & $58.2 \pm 5.2$ & $59.0 \pm 4.0$ & $59.4 \pm 3.3$ \\
\hline$T_{\mathrm{A} 3}$ & Min between 3rd post-incisional dose of fentanyl and end of infusion 2 & $23.1 \pm 7.8$ & $26.6 \pm 17.8$ & $23.0 \pm 8.4$ \\
\hline$T_{\mathrm{B} 1}+T_{\mathrm{A} 2}$ & Duration in min of first infusion & $81.2 \pm 8.3$ & $84.2 \pm 7.9$ & $82.6 \pm 8.3$ \\
\hline$T_{\mathrm{B} 2}+T_{\mathrm{A} 3}$ & Duration in min of second infusion & $81.3 \pm 8.0$ & $85.5 \pm 17.7$ & $82.4 \pm 8.8$ \\
\hline
\end{tabular}


This procedure was repeated until the patients were alert enough to begin self-administration using the PCA pump button. The PCA pump was set to deliver a $1.0-1.5 \mathrm{mg}$ i.v. bolus dose of morphine with a lock-out time of $5 \mathrm{~min}$, a maximum dose of $40 \mathrm{mg}$ in any $4 \mathrm{~h}$ period, and no continuous background infusion. This regimen was overseen by the Acute Pain Service and was continued on the ward for $72 \mathrm{~h}$ during which time no other analgesics were administered. Morphine consumption in milligrams was calculated on an hourly basis from hard copy records (Abbott TRW Printer, Model TP 40, Abbott Laboratories, Chicago, IL, USA) of the $72 \mathrm{~h}$ study period.

\subsubsection{Measurement of post-operative pain and von Frey thresholds}

VAS-R was measured 3,6,12, 24, 48, and $72 \mathrm{~h}$ after surgery. VAS-M, MPQ, von Frey TT and PT were measured at 24,48 , and $72 \mathrm{~h}$ after surgery.

\subsubsection{Two-week follow-up}

Patients were seen in the hospital on their first visit postdischarge approximately 2 weeks after surgery. An assessment of pain status since discharge was obtained and von Frey touch (TT) and pain (PT) thresholds were measured as previously described.

\subsubsection{Six-month follow-up}

Patients were contacted by telephone approximately 6 months from the date of surgery and administered the postsurgical follow-up questionnaire. A maximum of five attempts was made to contact each patient by telephone.

\subsubsection{Sample size calculation}

Sample size estimation was performed using data from an earlier study of men undergoing radical prostatectomy who received pre-incisional or post-incisional lumbar epidural bupivacaine (Katz et al., 1994). In that study, mean cumulative PCA morphine was $55 \mathrm{mg}$ for the preincisional group and $71 \mathrm{mg}$ for the post-incisional group with a standard deviation of $28 \mathrm{mg}$. The $16 \mathrm{mg}$ difference in morphine consumption represented a savings of $30 \%$ in favor of the pre-incisional group. Using a type I error rate of 0.05 we estimated that we would require 45 patients per group to detect a mean difference of $16 \mathrm{mg}$ (SD $28 \mathrm{mg}$ ) with a power of $\sim 80 \%$ (Brown et al., 1993). Two Monte Carlo simulations (Hammersley and Handscomb, 1964) of 10,000 trials each were then performed under the following two conditions assuming 45 patients per group and a standard deviation of $28 \mathrm{mg}$ : (1) pre-incision mean $55 \mathrm{mg}$, postincision mean $71 \mathrm{mg}$, control mean $85 \mathrm{mg}$; and (2) preincision mean $55 \mathrm{mg}$, post-incision mean $=$ control mean $=71 \mathrm{mg}$. Comparisons between pairs of means were undertaken when the omnibus $F$-test was statistically significant (i.e. $\alpha=0.05$, two tailed). The Monte Carlo simulations indicated that a sample size of 45 patients per group provided a power of $80 \%$ under condition 1 and $99 \%$ under condition 2.

\subsubsection{Data entry and verification}

Data were keyed in twice. One of the data sets was checked for errors manually by two research assistants/nurses. After correcting any errors, the two data sets were compared field by field by an in-house computer program. Discrepancies between matching records in the two data sets were corrected by referring back to the raw data.

\subsubsection{Statistical analysis}

Data were analyzed using the Statistical Package for the Social Sciences (SPSS for Windows, release 11.0.1, Chicago, IL) and Primer of Biostatistics: The Program (Version 4.0, McGraw Hill, New York, NY, USA) (Glantz, 1997). Background demographic data and clinical variables were compared using ANOVA for parametric data and $\chi^{2}$-test for nominal data.

Primary outcome variable. Cumulative morphine consumption at $72 \mathrm{~h}$ after surgery was analyzed by one-way ANOVA followed by directional comparisons between pairs of means.

Secondary outcome variables. Visual analogue pain scores at rest (VAS-R), after movement (VAS-M) and von Frey touch (TT) and pain thresholds (PT) were analyzed by 2-way between-within ANOVA using group as the between subjects factor and time after surgery as the within subjects factor. The regression lines relating time and cumulative morphine consumption on day 3 after surgery (between 49 and $72 \mathrm{~h}$ ) were compared pair wise by one-way ANOVA by first testing the overall coincidence of the regression lines (Glantz, 1997). If the overall coincidence differed, the slopes and intercepts were compared by $t$-test using the Bonferroni type I error rate correction for multiple comparisons ( $\alpha=0.05 /$ number of comparisons). MPQ pain rating indexes (PRIs) and MPQ present pain intensity (PPI) were analyzed by non-parametric Kruskal-Wallis ANOVA of ranks. MHI and STAI-S scores were analyzed by one-way ANOVA.

All data presented are mean $\pm \mathrm{SD}$ unless otherwise specified. $P \leq 0.05$ is considered statistically significant.

\section{Results}

\subsection{Recruitment and patient withdrawals}

Between June 1994 and October 1997, 168 patients were recruited into the study. In total 25 patients were withdrawn for the following reasons.

Pre-randomization dropouts $(n=8)$ : Procedure cancelled on the day of surgery $(n=2)$; pharmacy did not prepare the drugs in time for the surgery $(n=2)$; personnel not available to run the case $(n=4)$.

Intraoperative withdrawals $(n=10)$ : Excessive bleeding and/or change in operative procedure $(n=4)$; 
administration of additional analgesic agents $(n=3)$; problems with the infusion pump $(n=2)$; anaphylactic reaction to general anesthesia $(n=1)$.

Postoperative withdrawals $(n=7)$ : bleeding $(n=1)$; faulty PCA equipment $(n=1)$; severe bladder spasms requiring additional analgesics $(n=3)$; alcohol withdrawal/delirium tremens $(n=1)$; excessive drowsiness precluding data collection $(n=1)$.

There were no significant differences among groups in the proportion of patients withdrawn $(n=7,6$, and 4 for groups 1-3, respectively).

In total, 143 patients completed the study; 47 in group 1, 50 in group 2 and 46 in group 3.

\subsection{Timing of drug administration relative to intraoperative events}

Table 1 and Fig. 1 show the intervals between specific intraoperative events as they relate to the time of administration of fentanyl, ketamine and saline. As designed, there were no significant group differences between any of the intervals, including, the time between the pre-induction dose of fentanyl and induction, the time between the start of the first infusion and incision, and the duration of the first and second infusions.

\subsection{Demographic, psychosocial and intraoperative variables}

There were no significant differences among the groups in demographic or clinical data (Table 2) or pre-operative MHI and STAI-S scores (Table 3). The groups did not differ significantly in the total dose of i.v. fentanyl. Groups 1 and 2 did not differ significantly in the total dose of ketamine received.

Figs. 2 and 3 show mean percent end tidal isoflurane and the mean change from pre-operative baseline level in heart rate and mean blood pressure across the surgical procedure. There were no significant differences among the three groups in any of these parameters.

Table 2

Demographic and clinical variables

\begin{tabular}{llll}
\hline $\begin{array}{l}\text { Demographic/ } \\
\text { clinical measure }\end{array}$ & Group 1 & Group 2 & Group 3 \\
\hline Age (years) & $62 \pm 5.8$ & $62 \pm 6.2$ & $61 \pm 6.7$ \\
Height $(\mathrm{cm})$ & $175 \pm 8.3$ & $178 \pm 7.9$ & $176 \pm 6.1$ \\
Weight $(\mathrm{kg})$ & $81 \pm 9.5$ & $84 \pm 17.1$ & $84 \pm 16.8$ \\
Frequency of & $25: 21$ & $18: 32$ & $23: 23$ \\
ASA status (1:2) & & & \\
Surgery duration (min) & $180 \pm 30.9$ & $181 \pm 30.7$ & $182 \pm 45.2$ \\
Blood loss $(\mathrm{ml})$ & $1507 \pm 983.5$ & $1770 \pm 1217.7$ & $1603 \pm 1015.7$ \\
Total fentanyl $(\mu \mathrm{g})$ & $364.8 \pm 59.66$ & $365.1 \pm 61.84$ & $369.9 \pm 87.24$ \\
Total ketamine $(\mathrm{mg})$ & $31.9 \pm 4.21$ & $32.2 \pm 3.9$ & $0.0 \pm 0.0$ \\
\hline
\end{tabular}

Data are mean \pm SD unless otherwise stated.
Table 3

Scores (mean \pm SD) on the Spielberger State Anxiety Inventory (STAI-S) and Mental Health Inventory (MHI) obtained the evening before surgery

\begin{tabular}{llll}
\hline Psychosocial measure & Group 1 & Group 2 & Group 3 \\
\hline STAI-S & $38.1 \pm 9.63$ & $35.8 \pm 10.87$ & $34.8 \pm 8.77$ \\
MHI-anxiety & $24.4 \pm 3.33$ & $24.2 \pm 4.42$ & $25.4 \pm 3.63$ \\
MHI-depression & $20.9 \pm 2.40$ & $21.1 \pm 3.28$ & $21.5 \pm 2.70$ \\
MHI-loss of control & $22.1 \pm 2.12$ & $22.1 \pm 1.95$ & $22.2 \pm 1.94$ \\
MHI-positive affect & $18.7 \pm 3.09$ & $18.4 \pm 3.12$ & $19.3 \pm 2.34$ \\
MHI-total score & $91.5 \pm 10.45$ & $91.3 \pm 11.64$ & $93.9 \pm 9.04$ \\
\hline
\end{tabular}

\subsection{PCA morphine consumption}

Although cumulative PCA morphine consumption at $72 \mathrm{~h}$ was lower in group $1(92.3 \pm 45.9 \mathrm{mg})$ than group 2 $(107.2 \pm 58.4 \mathrm{mg})$ and group $3(103.6 \pm 50.4 \mathrm{mg})$, comparisons between the means did not reach the conventional 0.05 level of significance $(P=0.08$ for groups 1 vs. 2 and $P=0.08$ for groups 1 vs. 3 ). The number of PCA requests that did not result in a bolus of morphine (i.e. requests made during the 5-min lock-out period) did not differ significantly among the groups (data not shown). Table 4 shows PCA morphine consumption between intervals when pain at rest was assessed. Morphine consumption did not differ significantly during any of the intervals.

Fig. 4 shows cumulative morphine consumption for the three groups across the $72 \mathrm{~h}$ study period. Also shown are the best-fitting linear regression lines relating cumulative morphine consumption and time for each group across the final $24 \mathrm{~h}$ period (day $3,49-72 \mathrm{~h}$ ). On day 3 , the hourly rate (mean \pm SEM) of morphine consumption in group $1\left(0.61 \pm 0.013 \mathrm{mg} \mathrm{h}^{-1}\right)$ was significantly lower $(P<0.0009)$ than that in group $2\left(0.86 \pm 0.011 \mathrm{mg} \mathrm{h}^{-1}\right)$ and group $3\left(0.89 \pm 0.008 \mathrm{mg} \mathrm{h}^{-1}\right)$. Groups 2 and 3 did not differ significantly.

\subsection{Postoperative pain and von Frey thresholds}

There were no significant differences among the groups in VAS pain scores (Fig. 5), MPQ pain rating indexes

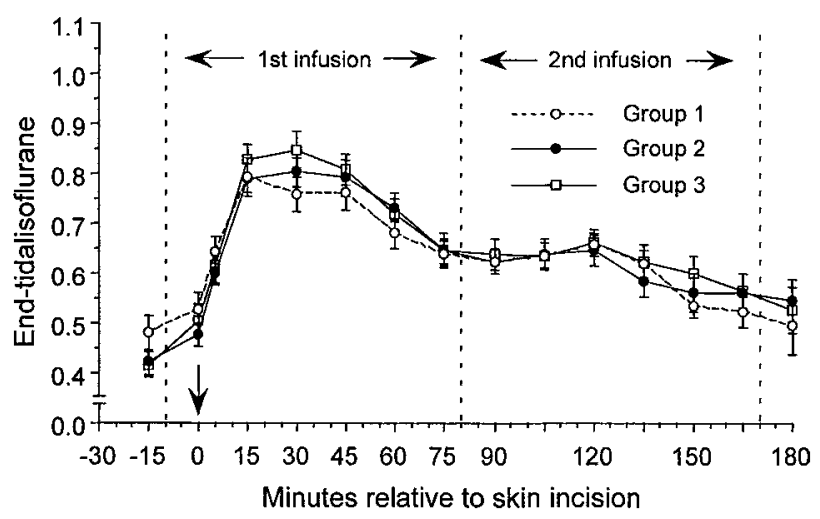

Fig. 2. Percent end-tidal isoflurane shown for the three groups during the first and second intraoperative i.v. infusions. Downward pointing arrow at zero on the $X$-axis corresponds to time of skin incision. 

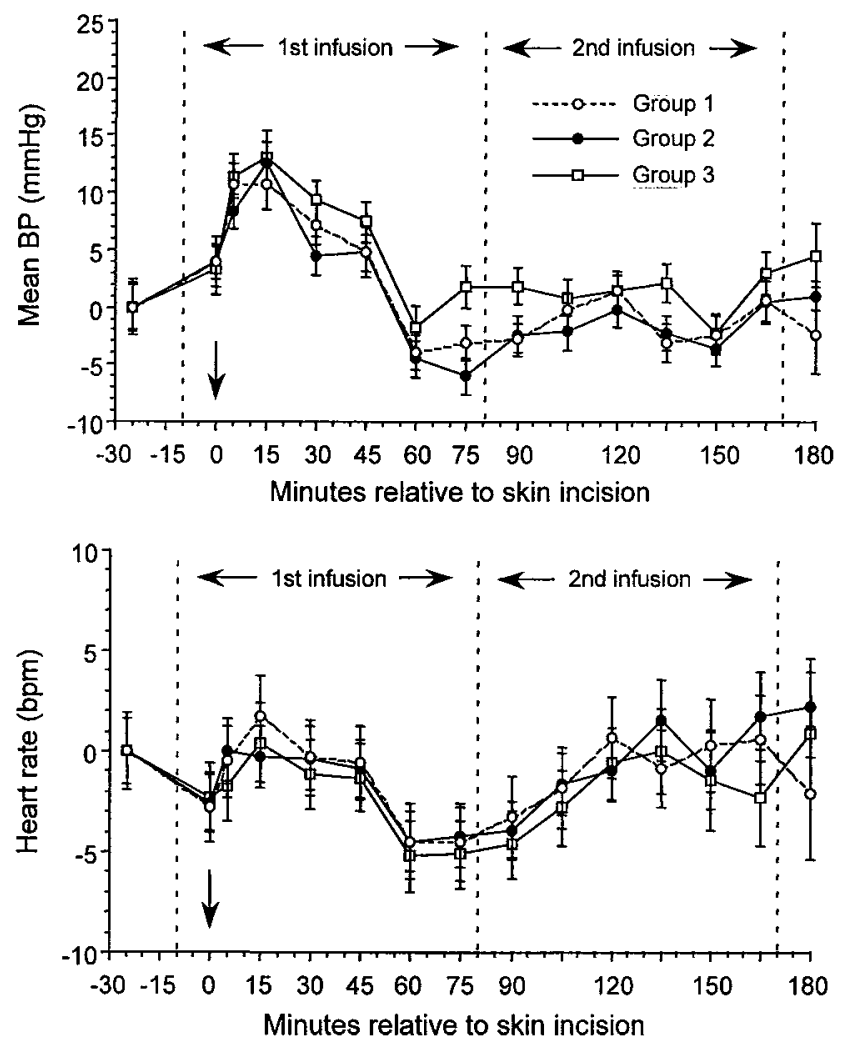

Fig. 3. Change from baseline in mean blood pressure and heart rate shown for the three groups during the first and second intraoperative i.v. infusions. Downward pointing arrow at zero on the $X$-axis corresponds to time of skin incision.

(Table 5), or von Frey touch or pain thresholds measured near the wound and at the control site on the inner forearm (Fig. 6)

\subsection{Complications/adverse events}

The following complications/adverse events occurred intraoperatively: excessive bleeding in two patients (one in group 1 and one in group 3); anaphylactic reaction to the general anesthetic in one patient (group 2). The following complications/adverse events occurred post-operatively: vivid dreams in one patient (group 2); agitation in two patients (one in group 1 and one in group 3); drowsiness in

Table 4

PCA morphine consumption (mg) within intervals bounded by times when pain at rest was assessed

\begin{tabular}{lccc}
\hline $\begin{array}{l}\text { Time interval } \\
\text { after surgery }(\mathrm{h})\end{array}$ & Group 1 & Group 2 & Group 3 \\
\hline $0-3$ & $14.5 \pm 7.9$ & $14.7 \pm 9.1$ & $15.2 \pm 7.4$ \\
$3-6$ & $5.7 \pm 5.0$ & $7.4 \pm 5.4$ & $5.7 \pm 3.9$ \\
$6-12$ & $7.8 \pm 4.9$ & $9.1 \pm 7.1$ & $8.7 \pm 6.6$ \\
$12-24$ & $20.2 \pm 11.3$ & $24.1 \pm 15.2$ & $22.7 \pm 14.9$ \\
$24-48$ & $28.1 \pm 16.4$ & $30.1 \pm 20.1$ & $29.8 \pm 17.3$ \\
$48-72$ & $16.0 \pm 15.7$ & $21.7 \pm 20.0$ & $21.5 \pm 18.9$ \\
\hline
\end{tabular}

Data are mean \pm SD.

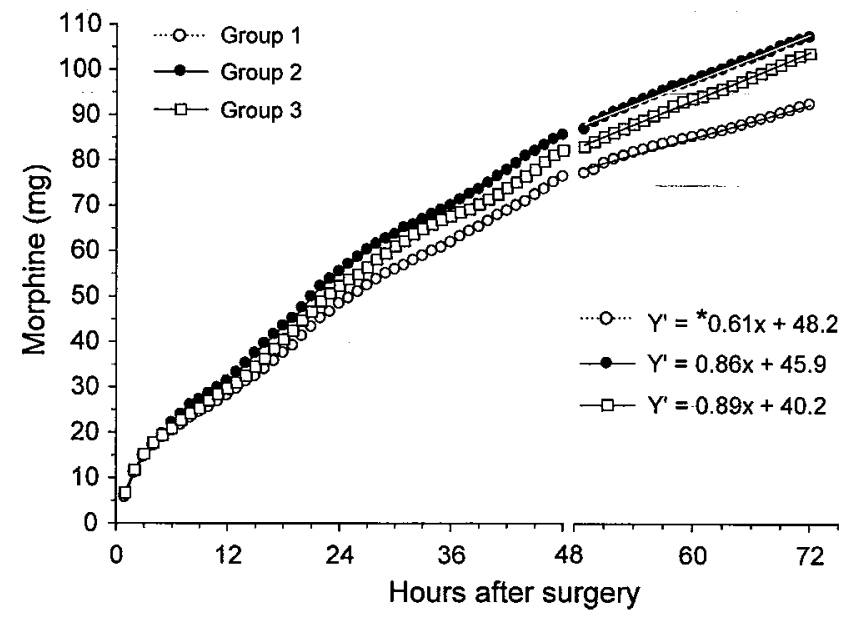

Fig. 4. An hour-by-hour plot of cumulative PCA morphine consumption for each group showing the best-fitting, least squares regression line calculated for day 3 (49-72 $\mathrm{h}$ after surgery). Each regression line accounts for at least 95\% $\left(r^{2}\right)$ of the total variance. The hourly rate of morphine consumption on day 3 was significantly lower for groups 1 vs. 2 and for groups 1 vs. 3 reflecting the benefit of pre-operative ketamine. Bonferroni corrected significance tests of the regression line slope comparing groups 1 vs. 2 and groups 1 vs. 3 on day $3, * P<0.0009$.

two patients (group 1); alcohol withdrawal/delirium tremens in one patient (group 2); and hypotension and bleeding in one patient (group 3).

\subsection{Two-week follow-up assessment}

One hundred and twenty-five of the 143 patients $(87.4 \%)$ were assessed at the hospital approximately 2 weeks after discharge ( $n=40,43$, and 42 in groups $1-3$, respectively). The overall incidence of pain was $55.2 \%(n=79)$. The pain intensity was in the mild to moderate range. von Frey touch and pain thresholds are shown in Fig. 6. There were no significant differences among the three groups in any of the variables measured (Table 6).

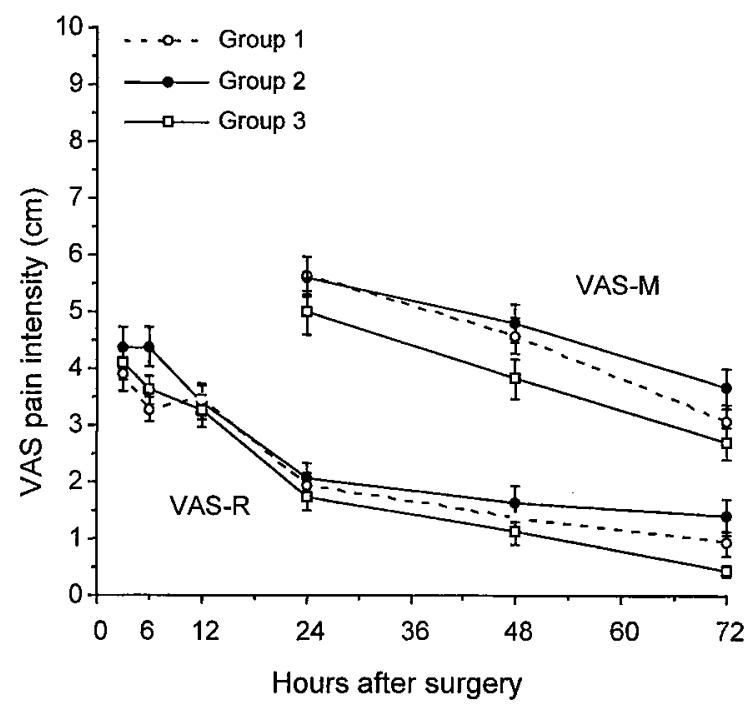

Fig. 5. Visual analogue scale (VAS) pain scores at rest (R) and after standardized movement $(\mathrm{M})$. Data are mean and standard deviation. 
Table 5

McGill Pain Questionnaire (MPQ) pain rating index (PRI) for sensory (S), affective (A), evaluative (E), miscellaneous (M) and total (T) scores, present pain intensity (PPI) and number of words chosen (NWC)

\begin{tabular}{|c|c|c|c|c|c|c|c|c|c|}
\hline \multirow[t]{2}{*}{ MPQ scores } & \multicolumn{3}{|c|}{ Day 1 (24 h) post-op } & \multicolumn{3}{|c|}{ Day $2(48 \mathrm{~h})$ post-op } & \multicolumn{3}{|c|}{ Day $3(72 \mathrm{~h})$ post-op } \\
\hline & Group 1 & Group 2 & Group 3 & Group 1 & Group 2 & Group 3 & Group 1 & Group 2 & Group 3 \\
\hline PRI-S & $8.0 \pm 7.0$ & $6.9 \pm 7.1$ & $7.6 \pm 6.3$ & $6.2 \pm 7.0$ & $4.4 \pm 5.2$ & $4.4 \pm 4.8$ & $4.0 \pm 5.7$ & $4.4 \pm 5.3$ & $2.6 \pm 4.0$ \\
\hline PRI-A & $0.7 \pm 1.1$ & $0.7 \pm 1.2$ & $0.7 \pm 1.5$ & $0.8 \pm 2.1$ & $0.7 \pm 1.4$ & $0.4 \pm 1.0$ & $0.3 \pm 0.7$ & $0.3 \pm 0.7$ & $0.1 \pm 0.3$ \\
\hline PRI-E & $1.1 \pm 1.2$ & $0.9 \pm 1.2$ & $1.0 \pm 1.3$ & $0.9 \pm 1.4$ & $0.5 \pm 0.8$ & $0.5 \pm 1.0$ & $0.6 \pm 1.1$ & $0.6 \pm 1.1$ & $0.2 \pm 0.5$ \\
\hline PRI-M & $1.7 \pm 2.5$ & $1.4 \pm 2.0$ & $1.7 \pm 2.2$ & $1.2 \pm 1.9 \ldots$ & $1.6 \pm 2.6$ & $1.1 \pm 2.2$ & $0.6 \pm 1.4$ & $0.5 \pm 0.8$ & $0.5 \pm 1.0$ \\
\hline PRI-T & $11.5 \pm 10.1$ & $9.9 \pm 10.4$ & $11.1 \pm 9.5$ & $9.1 \pm 11.4$ & $7.2 \pm 8.6$ & $6.5 \pm 7.1$ & $5.5 \pm 7.8$ & $5.9 \pm 7.1$ & $3.3 \pm 5.1$ \\
\hline PPI & $1.3 \pm 0.8$ & $1.3 \pm 0.9$ & $1.4 \pm 0.9$ & $1.2 \pm 1.3$ & $1.0 \pm 1.1$ & $1.1 \pm 1.0$ & $0.7 \pm 0.9$ & $0.9 \pm 1.0$ & $0.6 \pm 0.8$ \\
\hline NWC & $7.0 \pm 5.9$ & $5.7 \pm 5.6$ & $6.3 \pm 4.9$ & $5.8 \pm 7.3$ & $4.0 \pm 4.5$ & $3.8 \pm 4.1$ & $3.3 \pm 4.8$ & $3.8 \pm 4.8$ & $1.9 \pm 2.8$ \\
\hline
\end{tabular}

Data are mean \pm SD.

\subsection{Six-month follow-up interview}

One hundred and eight of the 143 patients $(75.5 \%)$ were reached by telephone 6 months after surgery ( $n=34,36$, and 38 in groups $1-3$, respectively). The groups did not differ significantly in the most intense pain they remembered having experienced after surgery (Table 7) which was a remarkably accurate reflection of their $24 \mathrm{~h}$ VAS-M pain scores (Fig. 5).

The overall incidence of pain was $10.5 \%(n=15)$ with no significant difference among the three groups (Table 7). The pain was described as sharp, burning or aching and as originating in deep tissue and at the scar. In general, the intensity of pain was mild and all 15 patients reported not taking analgesic medication for the pain. One patient in group 2 reported that the pain interfered 'slightly' with his everyday activities; the remaining 14 reported no interference at all.

\section{Discussion}

The results of the present study do not support the hypothesis that pre-operative i.v. administration of the NMDA receptor antagonist ketamine results in a clinically meaningful reduction in pain or morphine consumption when compared with a saline control condition or postincisional administration of i.v. ketamine. In the present study, a bolus dose of $0.2 \mathrm{mg} \mathrm{kg}^{-1}$ ketamine followed by continuous infusion of $2.5 \mu \mathrm{g} \mathrm{kg}^{-1} \mathrm{~min}^{-1}$ for $80 \mathrm{~min}$ was started $10 \mathrm{~min}$ before or $70 \mathrm{~min}$ after incision. This amounted to approximately $30 \mathrm{mg}$ ketamine administered over the duration of the 3 -h procedure. There was no evidence that post-operative pain or analgesic use differed as a function of pre-operative or post-incisional administration of ketamine. Nor did this regimen reduce postoperative cumulative morphine consumption or pain compared with a saline control group that did not receive ketamine.

However, between group comparisons of the regression line slopes relating morphine and time support the idea that pre-operative ketamine is associated with a late reduction in the rate of morphine consumption beginning at $49 \mathrm{~h}$ after surgery and extending to the end of the study, $72 \mathrm{~h}$ after surgery. The difference in the rate of morphine consumption between group 1 and the other two groups on day 3 was approximately $0.25 \mathrm{mg} \mathrm{h}^{-1}$ (Fig. 4) amounting to $6 \mathrm{mg}$ less of morphine over $24 \mathrm{~h}$. Since this effect was observed two days after ketamine administration $(>15$ ketamine half lives; Clements et al., 1982) in groups 1 and 2, it is likely not related to the ongoing actions of the drug but rather to a possible reduction in central sensitization.

The difference in the rate of morphine consumption in favor of the pre-incisional group supports the idea that early and late noxious intraoperative stimuli contribute differentially to the establishment of central sensitization (Katz, 2003; Katz et al., 2003). In the present study, it appears that the noxious events during the early intraoperative period including incision and the following 70 min contribute to a greater extent to central sensitization than do noxious late intraoperative or post-operative stimuli. Furthermore, given the absence of a difference in rate of morphine consumption between groups 2 and 3, it would appear that the most

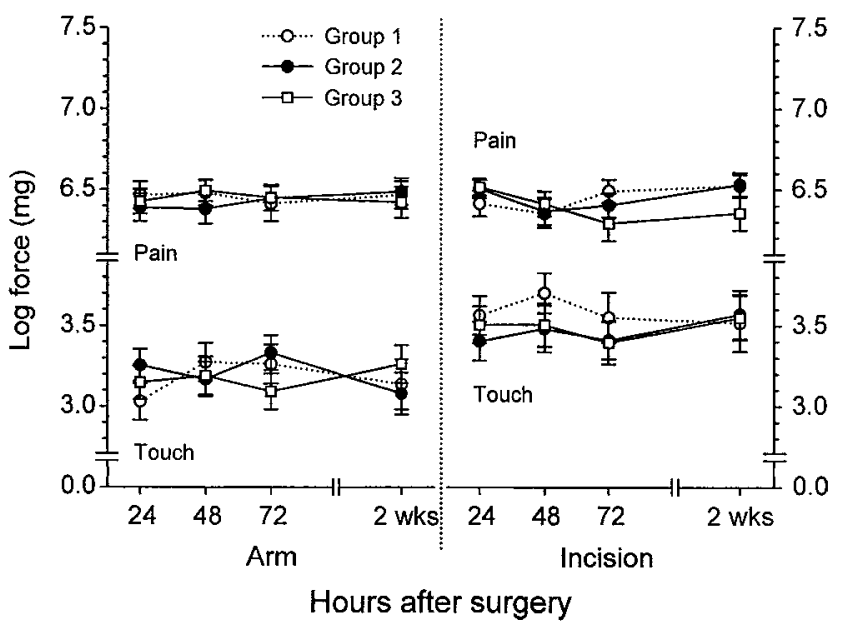

Fig. 6. von Frey touch and pain thresholds obtained $10 \mathrm{~cm}$ from the wound dressing and at a control site on the forearm. Data are mean and standard deviation. 
Table 6

Data $[n(\%)]$ from 2-week post-discharge follow-up

\begin{tabular}{llll}
\hline Follow-up measure & Group 1 & Group 2 & Group 3 \\
\hline Days since surgery (mean \pm SD) & $18.9 \pm 4.4$ & $19.7 \pm 10.7$ & $19.6 \pm 4.6$ \\
VAS pain at rest (mean \pm SD) & $2.8 \pm 1.5$ & $3.0 \pm 1.7$ & $2.9 \pm 1.9$ \\
Pain-free on discharge (\%) & $25(62.5)$ & $24(55.8)$ & $25(61.0)$ \\
Pain since discharge (\%) & $23(57.5)$ & $30(69.8)$ & $26(63.4)$ \\
Scar tender to touch (\%) & $21(52.5)$ & $23(53.5)$ & $22(53.7)$ \\
\hline
\end{tabular}

important contribution to central sensitization in the present study originates in the effects of the barrage of noxious impulses arising from incision and subsequent noxious events. Nevertheless, the clinical significance of this effect is small and the somewhat lower morphine consumption was not accompanied by differences in pain hypersensitivity as measured by von Frey filaments, by pain scores at rest or after mobilization, or in the incidence and intensity of pain 2 weeks and 6 months after surgery.

The present design thus compared an early vs. late intraoperative start to NMDA receptor blockade by a low dose of ketamine. The timing of administration of the ketamine infusions and total dose of ketamine were designed to reduce the incidence of adverse reactions. Because of reports of psychotomimetic and emergence reactions associated ketamine (Sethna et al., 1998; White et al., 1982), we planned to stop the second infusion approximately $20-30 \mathrm{~min}$ before the end of surgery so as to minimize the potential occurrence of these adverse effects, especially in group 2 patients. We anticipated the mean duration of the radical prostatectomy procedure to be $3 \mathrm{~h}$ as in our earlier study (Katz et al., 1994) so that running the two infusions for approximately $80 \mathrm{~min}$ each translated into

Table 7

Six-month follow-up data

\begin{tabular}{|c|c|c|c|}
\hline Follow-up measure & Group 1 & Group 2 & Group 3 \\
\hline Follow up time in days & $201.8 \pm 17.8$ & $204.7 \pm 19.3$ & $205.2 \pm 25.2$ \\
\hline \multicolumn{4}{|l|}{ Most intense pain after surgery } \\
\hline PPI $(0-5)$ & $2.1 \pm 0.6$ & $2.1 \pm 0.7$ & $2.0 \pm 0.9$ \\
\hline VRS $(0-10)$ & $5.1 \pm 1.9$ & $5.6 \pm 2.2$ & $5.1 \pm 2.5$ \\
\hline $\begin{array}{l}\text { Has pain at site of surgery } \\
{[n(\%)]}\end{array}$ & $6(17.6)$ & $2(5.6)$ & $7(8.4)$ \\
\hline Taking medication $[n]$ & 0 & 0 & 0 \\
\hline \multicolumn{4}{|c|}{ Pain interference in daily activities } \\
\hline Not at all $[n(\%)]$ & $6(100)$ & $1(50)$ & $7(100)$ \\
\hline Slightly $[n(\%)]$ & $0(0)$ & $1(50)$ & $0(0)$ \\
\hline VAS-rest pain & $2.3 \pm 1.2$ & $2.8 \pm 1.1$ & $3.4 \pm 3.0$ \\
\hline \multicolumn{4}{|c|}{ McGill Pain Questionnaire scores } \\
\hline PRI-sensory & $2.4 \pm 2.1$ & $2.0 \pm 1.4$ & $3.9 \pm 2.7$ \\
\hline PRI-affective & $0.0 \pm 0.0$ & $0.0 \pm 0.0$ & $0.0 \pm 0.0$ \\
\hline PRI-evaluative & $0.6 \pm 0.5$ & $1.0 \pm 0.0$ & $0.4 \pm 0.5$ \\
\hline PRI-total & $3.0 \pm 2.1$ & $3.0 \pm 1.4$ & $4.9 \pm 2.8$ \\
\hline Present pain intensity & $1.4 \pm 0.5$ & $1.0 \pm 0.0$ & $1.7 \pm 1.5$ \\
\hline Number of words chosen & $2.2 \pm 1.3$ & $2.5 \pm 0.7$ & $3.1 \pm 1.5$ \\
\hline
\end{tabular}

Follow-up time and most intense pain are reported for all 108 patients reached. The remaining variables show data only for patients reporting pain. Data are mean \pm SD unless otherwise stated. stopping the second infusion on average $30 \mathrm{~min}$ before the end of surgery (Table 1 and Fig. 1). Emergence reactions were not observed; nor were hallucinations or other psychotomimetic effects although one patient in group 2 reported having had vivid dreams.

The low dose of ketamine also appeared to have no effect on intraoperative heart rate or blood pressure in contrast to the results reported by Roytblat et al. (1993) showing a marked reduction in intraoperative hemodynamics associated with a single pre-operative bolus dose of $0.15 \mathrm{mg} \mathrm{kg}^{-1}$ ketamine i.v. As shown in Figs. 2 and 3 isoflurane requirements and hemodynamic responses did not significantly differ among the three groups, nor between the first and second infusions within groups 1 and 2. To our knowledge, the only other study to compare low dose ketamine $\left(0.15 \mathrm{mg} \mathrm{kg}^{-1}\right)$ and saline also reported no significant differences in intraoperative heart rate and blood pressure (Hirata et al., 1995).

There are several possibilities that alone, or in various combinations, may explain the lack of a clinically significant pre-emptive or preventive effect of the fentanyl and ketamine used in the present study. The first has to do with the related issues of timing of ketamine administration relative to incision and duration of NMDA receptor blockade. Central sensitization is not only induced during surgery but also post-operatively by inflammatory inputs (Katz, 2003; Kissin, 2000). As discussed above, neither group 1 nor group 2 received the ketamine infusion for the duration of the surgical procedure and no ketamine was given in the post-operative period. Thus, the modest effects in rate of morphine consumption we observed might have been enhanced had we started the infusion before surgery and continued it throughout the procedure into the postoperative period.

Secondly, the dose of ketamine used in the present study may have been too small. Studies of abdominal surgery patients have reported significant effects using bolus doses that ranged between 0.15 and $2 \mathrm{mg} \mathrm{kg}^{-1}$ and infusion rates between $\sim 8$ and $20 \mu \mathrm{g} \mathrm{kg}^{-1} \mathrm{~min}^{-1}$ (Aida et al., 2000; Fu et al., 1997; Kee et al., 1997; Roytblat et al., 1993; Tverskoy et al., 1994). Negative results have also been reported after abdominal hysterectomy using a total ketamine dose approximating the $30 \mathrm{mg}$ used in the present study (Wilder-Smith et al., 1998). Other surgical procedures have produced mixed results: the same small bolus dose of $0.15 \mathrm{mg} \mathrm{kg}^{-1}$ ketamine produced an early opposite effect in favor of the post-incision group after mastectomy (Adam et al., 1999) and significantly lower post-operative morphine requirements $48 \mathrm{~h}$ after anterior cruciate ligament repair in patients treated with ketamine before or after surgery compared with a placebo control group (Menigaux et al., 2000). In addition, a considerable amount of blood loss occurred in all three groups (Table 2) which, together with the associated fluid management, may have reduced further the ketamine serum concentration in groups 1 and 2 . It is possible that a larger dose of ketamine combined with 
a continuous intravenous infusion would have resulted in more clinically significant results in the present study.

A third reason for the lack of a clinically significant effect may have to do with the co-administration of fentanyl with ketamine and more generally; the role of ketamine in potentiating opioid analgesia by preventing or reducing central sensitization. Our expectation was that adding lowdose ketamine to a standard general anesthetic regimen using fentanyl would produce enhanced antinociceptive effects due to the combined actions of the two agents operating at different receptor sites (Chapman and Dickenson, 1992; Dickenson, 1997), and in particular by preventing or obtunding the NMDA-mediated state of pain hypersensitivity that normally ensues following tissue damage (Dickenson, 1997). However, the results of a recent rat study in which epidural ketamine was combined with various doses of morphine and fentanyl suggests that the effects of ketamine may depend on the specific mu opioid agonist (Hoffmann et al., 2003). Whereas ketamine potentiated the antinociceptive effects of morphine, it antagonized the effects of fentanyl at several doses. The mechanism by which this antagonistic effect occurred is not known but may involve competition for active blood-brain barrier transport proteins due to the high lipophilicity of both ketamine and fentanyl, competition between ketamine and fentanyl for the mu receptor, drug differences in mu receptor subtype binding, or intracellular differences in phosphorylation associated with specific opioid-ketamine combinations (Hoffmann et al., 2003).

To date six studies have evaluated pre-emptive or preventive effects of i.v. ketamine in combination with an opioid. The clinical data do not point to a clear-cut relationship between the relative efficacy of ketamine when administered with various opioid agonists although Hoffmann et al. (2003) suggested that lipophilicity may be a factor. The two studies that administered ketamine in combination with morphine found a significant opioid sparing effect (Aida et al., 2000; Kee et al., 1997), and a significant reduction in post-operative pain (Aida et al., 2000) compared with a control group. The only other study to have administered pre-operative ketamine with fentanyl also found a significant opioid sparing effect in favor of the ketamine treated patients compared with a saline control group (Roytblat et al., 1993). The remaining three studies did not find a pre-emptive or preventive effect when ketamine was administered in combination with the fastacting opioids sufentanil (Adam et al., 1999; Menigaux et al., 2000) or alfentanil (Dahl et al., 2000). Interestingly, co-administration of ketamine and alfentanil before or after surgery resulted in greater pain intensity when compared with a saline control group that received alfentanil alone (Dahl et al., 2000). These results were opposite in direction to what was predicted, and are consistent with the suggestion that ketamine may have antagonized the antinociceptive effects of the opioid (Hoffmann et al., 2003). Further studies are required to determine the relative efficacy of ketamine in combination with various opioid agonists.

The literature contains two competing hypotheses that may, in part, help to explain the negative findings of the present study. On the one hand, it is possible that the fentanyl and other agents (e.g. nitrous oxide), administered as part of the general anesthetic regimen, exerted subtle, additive pre-emptive effects, which may have attenuated the central sensitizing effects of surgery in all patients thereby minimizing the effect size when comparing groups 1 and 2 with the control group.

On the other hand, recent evidence shows that under certain conditions opioids activate pronociceptive systems associated with acute opioid tolerance and opioid-induced hyperalgesia (Celerier et al., 2000; Crain and Shen, 2000; Kissin et al., 2000; Mao et al., 1995). These phenomena are derived from an NMDA-receptor mediated mechanism similar to that which occurs following tissue damaging injury. Mu-opioid receptor agonists produce a sustained increase in NMDA-activated currents by activating intracellular protein kinase $\mathrm{C}$ which potentiates the NMDA response by reducing the voltage-dependent $\mathrm{Mg}^{2+}$ block of NMDA-receptor channels. In rats, pre-treatment with ketamine prior to opioid administration and followed by repeated ketamine injections prevented opioid-induced hyperalgesia and acute tolerance to opioids (Laulin et al., 2002). It is possible that administration of fentanyl to all patients may have activated a pronociceptive system thereby minimizing later inter-groups differences in postoperative pain and morphine consumption. The subsequent administration of ketamine to groups 1 and 2 after the fentanyl may have been too late to prevent opioid-induced NMDA-receptor activation.

Taken together, these results suggest that clinically significant reductions in post-operative pain and analgesic use are more likely to be found when ketamine is administered preventively (Katz, 2003; McCartney et al., 2004 ) before induction of anesthesia (prior to an opioid; preferably morphine) and continuously throughout the operation. In addition, use of the $\mathrm{S}(+)$ isomer of ketamine may produce more substantial results. The $\mathrm{S}(+)$ isomer has been shown to be 3-4 times more potent than the $\mathrm{R}(+)$ isomer in producing anti-nociceptive effects and, in equianalgesic doses, possibly to induce fewer psychotomimetic effects (Marietta et al., 1977; Mathisen et al., 1995; White et al., 1985). These suggestions appear to be supported by preliminary results (Snijdelaar et al., 2004).

In summary, pre-operative i.v. fentanyl plus a low-dose i.v. ketamine infusion did not reduce cumulative morphine consumption or pain, to a clinically significant extent, when compared with the same regimen initiated $70 \mathrm{~min}$ after the start of surgery or a fentanyl plus saline control condition. Although the rate of morphine consumption on day 3 was significantly lower in group 1 than in groups 2 and 3 , by 2 weeks and 6 months after surgery the three groups did not differ significantly in pain incidence or intensity. Extending 
the duration of the infusion to cover a longer period of nociceptive activity, use of the $S(+)$ isomer of ketamine, and co-administering it in combination with morphine may produce more clinically meaningful results.

\section{Acknowledgements}

The study was supported by Grants MT- 12052 and MOP-37845 from the Canadian Institutes of Health Research (CIHR), Ontario, Canada, and a CIHR Investigator Award to JK. JK is supported by a Canada Research Chair in Health Psychology at York University. TJC is supported by a CIHR Investigator Award. Presented in part at the 20th Annual Scientific Meeting of the American Pain Society, Phoenix, AZ, USA (April 21, 2001) and the Annual Conference of the Canadian Pain Society, Montreal, QC, Canada (May 10, 2001). We are grateful for the help provided by the staff of the Department of Anesthesia and Pain Management, Department of Urology and the PACU at the Toronto General Hospital, Toronto, Ont., Canada. The authors thank Tanya Constantine, Mariel Escover, Eileen Halket Olivera, Karanovic, Keitha McMurray, and Bart Mysliwiec for their expertise with patient care and/or help in data scoring, entry and verification.

\section{References}

Adam F, Libier M, Oszustowicz T, Lefebvre D, Beal J, Meynadier J. Preoperative small-dose ketamine has no preemptive analgesic effect in patients undergoing total mastectomy. Anesth Analg 1999;89: 444-7.

Aida S, Yamakura T, Baba H, Taga K, Fukuda S, Shimoji K. Preemptive analgesia by intravenous low-dose ketamine and epidural morphine in gastrectomy: a randomized double-blind study. Anesthesiology 2000; 92:1624-30.

Brown BW, Brauner C, Chan A, Gutierrez D, Herson J, Lovato J, Polsley J. STPLAN version 4.0: June, 1993. Calculations for sample sizes and related problems. Houston, TX: The University of Texas M.D. Anderson Cancer Center; 1993.

Celerier E, Rivat C, Jun Y, Laulin JP, Larcher A, Reynier P, Simonnet G. Long-lasting hyperalgesia induced by fentanyl in rats: preventive effect of ketamine. Anesthesiology 2000;92:465-72.

Chapman V, Dickenson AH. The combination of NMDA antagonism and morphine produces profound antinociception in the rat dorsal horn. Brain Res 1992;573:321-3.

Clements JA, Nimmo WS, Grant IS. Bioavailability, pharmacokinetics, and analgesic activity of ketamine in humans. J Pharm Sci 1982;71:539-42.

Crain SM, Shen KF. Antagonists of excitatory opioid receptor functions enhance morphine's analgesic potency and attenuate opioid tolerance/dependence liability. Pain 2000;84:121-31.

Dahl V, Ernoe PE, Steen T, Raeder JC, White PF. Does ketamine have preemptive effects in women undergoing abdominal hysterectomy procedures? Anesth Analg 2000;90:1419-22.

Dajczman E, Gordon A, Kriesman H, Wolklove N. Long-term postthoracotomy pain. Chest 1991;99:270-4.

Dallal GE. DESIGN: a supplementary module for SYSTAT and SYGRAPH, SYSTAT. Evanston, IL; 1988.

Dickenson AH. NMDA receptor antagonists: interactions with opioids. Acta Anaesthesiol Scand 1997;41:112-5.
Fu ES, Miguel R, Scharf JE. Preemptive ketamine decreases postoperative narcotic requirements in patients undergoing abdominal surgery. Anesth Analg 1997;84:1086-90.

Glantz SA. Primer of biostatistics: the program. New York: McGraw-Hill; 1997.

Hammersley JM, Handscomb DC. Monte Carlo methods. London: Methuen; 1964.

Hirata S, Seo N, Murayama T, Fujiwara T, Sekiguchi M. Addition of lowdose ketamine to general anesthesia does not improve cardiovascular response during conventional abdominal surgery. Anesth Analg 1995; $81: 1111-2$.

Hoffmann VL, Baker AK, Vercauteren MP, Adriaensen HF, Meert TF. Epidural ketamine potentiates epidural morphine but not fentanyl in acute nociception in rats. Eur J Pain 2003;7:121-30.

Katz J. Timing of treatment and pre-emptive analgesia. In: Rice A, Warfield C, Justins D, Eccleston C, editors. Clinical pain management: acute volume. London: Arnold; 2003. p. 113-62.

Katz J, Melzack R. Measurement of pain. Surg Clin North Am 1999;79: 231-52.

Katz J, Clairoux M, Kavanagh BP, Roger S, Nierenberg H, Redahan C, Sandler AN. Pre-emptive lumbar epidural anaesthesia reduces postoperative pain and patient-controlled morphine consumption after lower abdominal surgery. Pain 1994;59:395-403.

Katz J, Cohen L, Schmid R, Chan VW, Wowk A. Postoperative morphine use and hyperalgesia are reduced by preoperative but not intraoperative epidural analgesia: implications for preemptive analgesia and the prevention of central sensitization. Anesthesiology 2003;98:1449-60.

Kee WD, Khaw KS, Ma ML, Mainland PA, Gin T. Postoperative analgesic requirement after cesarean section: a comparison of anesthetic induction with ketamine or thiopental. Anesth Analg 1997;85:1294-8.

Kissin I. Preemptive analgesia. Anesthesiology 2000;93:1138-43.

Kissin I, Bright CA, Bradley Jr. EL. The effect of ketamine on opioidinduced acute tolerance: can it explain reduction of opioid consumption with ketamine-opioid analgesic combinations? Anesth Analg 2000;91: 1483-8.

Laulin JP, Maurette P, Corcuff JB, Rivat C, Chauvin M, Simonnet G. The role of ketamine in preventing fentanyl-induced hyperalgesia and subsequent acute morphine tolerance. Anesth Analg 2002;94: 1263-9.

Mao J, Price DD, Mayer DJ. Mechanisms of hyperalgesia and morphine tolerance: a current view of their possible interactions. Pain 1995;62: 259-74.

Marietta MP, Way WL, Castagnoli Jr. N, Trevor AJ. On the pharmacology of the ketamine enantiomorphs in the rat. J Pharmacol Exp Ther 1977; 202:157-65.

Mathisen LC, Skjelbred P, Skoglund LA, Oye I. Effect of ketamine, an NMDA receptor inhibitor, in acute and chronic orofacial pain. Pain 1995;61:215-20.

McCartney CJL, Sinha A, Katz J. A qualitative systematic review of the role of the $N$-methyl-D-aspartate (NMDA) receptor antagonists in preventive analgesia. Anesth Analg 2004;98:1385-400.

Melzack R. The McGill Pain Questionnaire: major properties and scoring methods. Pain 1975;1:277-99.

Menigaux C, Fletcher D, Dupont X, Guignard B, Guirimand F, Chauvin M. The benefits of intraoperative small-dose ketamine on postoperative pain after anterior cruciate ligament repair. Anesth Analg 2000;90: 129-35.

Roytblat L, Korotkoruchko A, Katz J, Glazer M, Greemberg L, Fisher A. Postoperative pain: the effect of low-dose ketamine in addition to general anesthesia. Anesth Analg 1993;77:1161-5.

Schmid RL, Sandler AN, Katz J. Use and efficacy of low-dose ketamine in the management of acute postoperative pain: a review of current techniques and outcomes. Pain 1999;82:111-25.

Sethna NF, Liu M, Gracely R, Bennett GJ, Max MB. Analgesic and cognitive effects of intravenous ketamine-alfentanil combinations versus either drug alone after intradermal capsaicin in normal subjects. Anesth Analg 1998;86:1250-6. 
Snijdelaar DG, Cornelisse HB, Schmid RL, Katz J. A randomised, controlled study of peri-operative low dose $s(+)$-ketamine in combination with postoperative patient-controlled $s(+)$-ketamine and morphine after radical prostatectomy. Anaesthesia 2004;59: 222-8.

Spielberger CD, Gorsuch RL, Lushene RE. STAI manual for the StateTrait Anxiety Inventory. Palo Alto, CA: Consulting Psychologists Press Inc.; 1970.

Tverskoy M, Oz Y, Isakson A, Finger J, Bradley Jr. EL, Kissin I. Preemptive effect of fentanyl and ketamine on postoperative pain and wound hyperalgesia. Anesth Analg 1994;78:205-9.

Ware JEJ, Johnston SA, Davies-Avery A, Brook RH. Conceptualization and measurement of health for adults in the Health Insurance Study. Vol. III. Mental health (R-1987/3-HEW). Santa Monica, CA: RAND Corporation; 1979.

Weinstein MC, Berwick DM, Goldman PA, Murphy JM, Barsky A. A comparison of three psychiatric screening tests using receiver operating characteristics (ROC) analysis. Med Care 1989;27: 593-607.
White PF, Way WL, Trevor AJ. Ketamine-its pharmacology and therapeutic uses. Anesthesiology 1982;56:119-36.

White-PF; Schuttler J, Shafer A, Stanski DR, Horai Y, Trevor AJ, Comparative pharmacology of the ketamine isomers. Studies in volunteers. Br J Anaesth 1985;57:197-203.

Wilcox GL. Excitatory neurotransmitters and pain. In: Bond MR, Charlton JE, Woolf CJ, editors. Proceedings of the VI World Congress on Pain. Amsterdam: Elsevier; 1991. p. 97-117.

Wilder-Smith OH, Arendt-Nielsen L, Gaumann D, Tassonyi E, Rifat KR. Sensory changes and pain after abdominal hysterectomy: a comparison of anesthetic supplementation with fentanyl versus magnesium or ketamine. Anesth Analg 1998;86:95-101.

Woolf CJ, Chong MS. Preemptive analgesia - treating postoperative pain by preventing the establishment of central sensitization. Anesth Analg 1993;77:362-79.

Woolf CJ, Thompson SW. The induction and maintenance of central sensitization is dependent on $\mathrm{N}$-methyl-D-aspartic acid receptor activation; implications for the treatment of post-injury pain hypersensitivity states. Pain 1991;44:293-9. 